\title{
Bone regeneration potential of sub-microfibrous membranes with osteogenic induction of rBMSC for tissue engineering
}

\author{
Yun-Hee Rhee ${ }^{1}$, Seong-Hwa $\mathrm{Oh}^{2}$, Hyun-Ju Lim${ }^{3}$, Jang-In Shin ${ }^{1}$, Chan Kim ${ }^{4}$ and \\ Chung-Hun Oh ${ }^{1,2,3 *}$ \\ ${ }^{1}$ Department of Oral Physiology, College of Dentistry, ${ }^{2}$ Department of Nanobiomedical Science \& WCU Research Center, \\ ${ }^{3}$ Department of Medical Laser, Graduate school, Dankook University, Cheonan, 330-714, ${ }^{4}$ AMOMEDI Co. Ltd, New Materials \\ Research Center, 597-2 Wonsanri, Hasungmyun, Kimpo, Kyungkido, 415-887, Republic of Korea
}

*For correspondence: Email: choh@dankook.ac.kr; Tel: +82-41-550-1918; Fax: +82-41-559-7906

\begin{abstract}
Purpose: To examine the biocompatibility and osteoinductive potential of sub-microfibrous membranes with cells in vitro and in vivo.

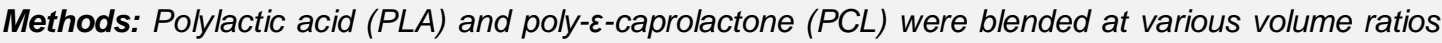
(PLA:PCL $=100: 0,70: 30,50: 50,30: 70$ and 0:100) and each membrane form was prepared by electrospinning. Cell viability, biocompatibility, and bone regeneration were measured.

Results: The membranes from the PLAVPCL blends prepared by an electrospinning process showed a range of diameter distribution ranging from 1,580 to $550 \mathrm{~nm}$. The cells of $100 \%$ PCL membrane (smallest diameter) exhibited significantly higher adhesion and proliferation than those of the other membranes. Among the membranes from PLAVPCL blends, PCL membrane showed weak inflammatory changes in the early stages of implantation without acute or chronic inflammation. PCL membranes with osteogenically-induced cells successfully stimulated new bone formation in a rate calvarial defect model.

Conclusion: The results indicate that biodegradable PCL sub-microfibrous membrane produced by electrospinning process seems to have excellent biocompatibility, and may be used as a scaffold for bone tissue engineering.
\end{abstract}

Keywords: Biocompatibility, Hard tissue, Biomaterial availability, Bone remodeling, Polylactic acid, Poly- $\varepsilon$-caprolactone, Osteoinductive potential, Sub-microfibrous membranes

Tropical Journal of Pharmaceutical Research is indexed by Science Citation Index (SciSearch), Scopus, International Pharmaceutical Abstract, Chemical Abstracts, Embase, Index Copernicus, EBSCO, African Index Medicus, JournalSeek, Journal Citation Reports/Science Edition, Directory of Open Access Journals (DOAJ), African Journal Online, Bioline International, Open-J-Gate and Pharmacy Abstracts

\section{INTRODUCTION}

Fibrous membranes of biodegradable polymers fabricated by an electrospinning technique have been developed for medical applications such as vascular graft [1], skin substitution [2], nerve regeneration [3], bone tissue engineering [4], and guided bone regeneration for dental surgery [5]. Many studies have been devoted to evaluating the suitability of these applications for in vitro and in vivo models [6]. Biodegradable substance,

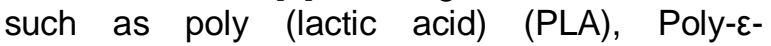
caprolactone (PCL), poly (glycolic acid) (PGA), and their copolymers, are regarded as the ideal materials for medical applications.

To develop an ideal biomaterial, we need to take into account not only its biocompatibility but also the balance between the biodegradation rate of exogenous polymers and the repair rate of the 
home tissue. Biodegradation rate is stimulated by penetration, attachment, growth, and differentiation of functional cells, but is inhibited by inflammatory responses and tissue rejection reactions. For optimal tissue engineering of damaged tissue, the biodegradation of the implanted scaffold, by host enzymatic and hydrolytic activities, must be followed by tissue replacement and functional restoration such as mechanical strength and original cellular activities.

Some studies have focused on the biodegradability [7], physic-chemical properties [8] and in vitro biocompatibility [2] of aliphatic polyesters and aliphatic polyester blends. In this work, two synthetic polymers were selected; poly- $\varepsilon$-caprolactone $(\mathrm{PCL})$ and poly-lactic acid (PLA). The polymers were blended at different ratios and were subjected to electrospinning. To examine biocompatibility of these membranes, human mesenchymal stem cells (hMSCs) were grown on the PCL/PLA composite membranes, and the tissue responses were examined in the subcutaneous tissues of mice. To assess the efficiency of bone formation, we evaluated the bone hilling activity stimulated by bone marrowderived stromal cells (BMCs) with or without osteogenic induction on the membranes in a rat calvarial defect model.

\section{EXPERIMENTAL}

\section{Preparation and characterization of fibrous membrane}

PLA (Sigma-Aldrich USA) and PCL (SigmaAldrich, USA) were separately dissolved in 2,2,2trifluoroethanol (TFE, Sigma-Aldrich). The volume ratio of PLA and PCL in the mixed solutions was either 100:0, 70:30, 50:50, 30:70 or $0: 100$. The mixed solutions were stirred for 24 h. Each solutions were applied into the $10 \mathrm{ml}$ syringe to electrospinning. An $15 \mathrm{kV}$ voltage was applied and the tip to collector distance was maintained at $10 \mathrm{~cm}$. The fibrous membranes were dried under vacuum to evaporate the solvent. The morphology of the samples was examined by scanning electron microscopy (SEM), and the diameter of the fibers was calculated from the SEM images.

\section{In vitro viability test}

Human mesenchymal stem cells (hMSC) were purchased from Lonza (Walkerville, USA) and maintained in Dulbecco's modified Eagle's medium (DMEM) containing $4.5 \mathrm{~g} / \mathrm{ml}$ D-glucose, $10 \% \mathrm{FBS}$, and $10 \mathrm{U} / \mathrm{ml}$ penicillin-streptomycin.
The proliferation of hMSCs on fibrous membranes was evaluated using a MTS assay (Promega, USA). Briefly, hMSCs were seeded at a density of $2 \times 10^{5}$ cells $/ \mathrm{cm}^{2}$ on various types of fibrous membranes in a 12-well plate at 0 days. The cells were cultured in the growth medium. Every $24 \mathrm{~h}$, an MTS solution was added to each well, incubated for $30 \mathrm{~min}$, and measured using a microplate reader (Molecular Devices, USA) at $450 \mathrm{~nm}$. The proliferation of hMSCs was observed by confocal microscopy. The cells were processed, as described in the MTS assay. All membranes were fixed with chilled ethanol every $24 \mathrm{~h}$, and $50 \mu \mathrm{g} / \mathrm{ml}$ propidium iodide solution was added to each well. The membranes with the cells were incubated for $15 \mathrm{~min}$ and washed with PBS briefly. Each time the number of cells in the fibrous membranes was counted and photographed by LSM510 confocal microscopy (Carl Zeiss, Switzerland).

\section{In vivo biocompatibility test}

The animal protocol used in this study was reviewed and approved based on ethical procedures and scientific care by the Dankook University-Institutional Animal Care and Use Committee (DKU-IACUC). To implant the fibrous membranes, incisions were cut on the dorsal section of each mouse and the fibrous membranes were and implanted into the incisions. The incisions were then sutured. After two weeks, the mice were sacrificed, and the entire graft was harvested with surrounding tissue. The samples were fixed with $4 \%$ paraformaldehyde and were subjected to Hematoxylin-Eosin staining.

\section{Assessment of bone regeneration in calvarial defects}

To evaluate whether bone marrow-derived stromal cells (BMCs) with osteoinduction participate in in vivo bone formation, a calvarial bone defect model was used for this assay in 8week-old Sprague-Dawley (SD) rats. BMCs were induced in osteogenic media for 7 days after growth in DMEM for 7 days. The osteogenic media consisted of $50 \mathrm{mM} \mathrm{L-ascorbic} \mathrm{2-}$ phosphate, $10 \mathrm{mM}$ glycerol-2-phosphate disodium, and $1 \mu \mathrm{M}$ dexamethasone, and the medium was replaced every 3 days.

Under general anesthesia, induced by an intramuscular injection of ketamine/rumpun (80 and $10 \mathrm{mg} / \mathrm{kg}$ ), the external cortical plates were removed using a 5-mm trephine bur with saline irrigation [9] [10]. One asymmetrical defect was made on the right side of the midline of each rat. Extreme care was taken not to harm the brain 
membranes. The bone defects were washed with normal saline, and membranes were then applied to the defects.

Animals were divided into three groups: Group 1, PCL membrane only $(n=3)$; Group 2, PCL membrane with non-induced rBMCs $(n=3)$; Group 3, PCL membrane with osteogenic induction of rBMCs $(n=3)$; No immunosuppressants were used. After 4 weeks, the rats were euthanized, and the transplanted constructs were dissected carefully and taken out of the surrounding soft tissue.

Microradiographs of the skull were performed using an Image Station FX (Kodak, Rochester, $\mathrm{NY}$ ) for $6 \mathrm{~s}$ at $12.5 \mathrm{kVp}$. After the radiographs had been taken, the defected calvaria samples were de-calcified with $20 \%$ EDTA. The samples were then dehydrated in a graded series of ethanol and embedded in paraffin. The center of the defect area was sectioned to a $4 \mu \mathrm{m}$ thickness, stained with Masson's Trichrome, and photographed using an optical microscope (Olympus BX51, Olympus, Miami, FL, USA).

\section{Statistical analysis}

All results are presented as mean and stabdard deviation (SD) and were evaluated using oneway analysis of variation (ANOVA) and also Tukey's analysis for pair wise comparison. Differences were considered significant at $p<$ 0.05 .

\section{RESULTS}

\section{Structural morphology of the fibrous membrane}

As shown in Figure 1, fibrous membranes produced from different volume ratios of PLA and PCL by an electrospinning technique led to a range of diameter distributions. The threedimensional fibrous structures with polygonal, interconnected pores and randomly oriented fibers were evaluated for their diameter range. The diameters of homogenous PLA fabrications was determined to be $1,580 \pm 232 \mathrm{~nm}$ (Figure 1A and F), PLA: $P C L=3: 7835 \pm 123 \mathrm{~nm}$ (Fig. 1B and G), PLA: PCL $=5: 5842 \pm 97 \mathrm{~nm}$ (Fig. $1 \mathrm{C}$ and H), PLA: $P C L=3: 7743 \pm 173 \mathrm{~nm}$ (Figure 1D and I), and the homogenous PCL $558 \pm 142 \mathrm{~nm}$ (Figure 1E and J).

\section{Viability of hMSC on the fibrous membrane}

The viability of the hMSCs on the fibrous membrane was examined using an MTS assay and PI staining (Fig. 2). On day 0, the hMSCs were seeded onto the various types of membrane, and their attachment and proliferation were observed after 7 days. As shown in Fig. 2a, the hMSCs were showed exponential growth patterns, without any cytotoxicity, for all types of membranes until day 4. Cells on PCL fibrous membranes showed a significantly higher viability than those on any of the other materials, and were in a relatively quiescent state throughout the 7 day period after seeding, compared to those of other membranes.

\section{In vivo biocompatibility}

Histological analysis by optical pathological microscopy was performed to make a comparison of the infiltration to various types of membrane. The pore size of the fibrous membranes is too small for cells to penetrate in vitro. However in vivo cellular infiltration was observed in the subcutaneous tissue of mice examined in week 2. As shown in Figure 3, histological examination of subcutaneous implantation with fibrous membranes revealed an infiltration of histiocytes and lymphocytes in the area of the margin and center, respectively. There was no evidence of acute or chronic inflammation in any groups. Our results showed that hypertrophy of lining histiocytes and infiltration of lymphocytes in the membranes gradually decreased with increasing ratio of PCL. However, the difference was not determined to be statistically significant $(p>0.5)$. For this reason, PCL seems to be a suitable candidate as a degradable fibrous membrane for use in biomaterials.

\section{Bone healing in rat calvarial defect model}

Bone regeneration effects were evaluated in the rat calvarial defect model by Soft x-ray and histological staining after four weeks. From the Soft x-ray observation (Figure 4B, implantation of fibrous membranes with non-induced rBMSC (group 2) to calvarial defected rats showed limited bone formation at the periphery, as did membrane only group (group 1). In contrast, implantation of the membrane with osteogenic induction of rBMSC (group 3) showed a significantly greater extent of bone healing, both on the inside and peripheral regions of the defect, compared to other groups. The quantitative analysis of bone density was consistent with Soft X-ray images. The relative bone regeneration area of group 3 was $0.73 \pm$ $0.08 \mathrm{~mm}$, which was significantly greater than that of group $2(0.36 \pm 0.07 \mathrm{~mm})$ and group 1 $(0.28 \pm 0.03 \mathrm{~mm})$. 

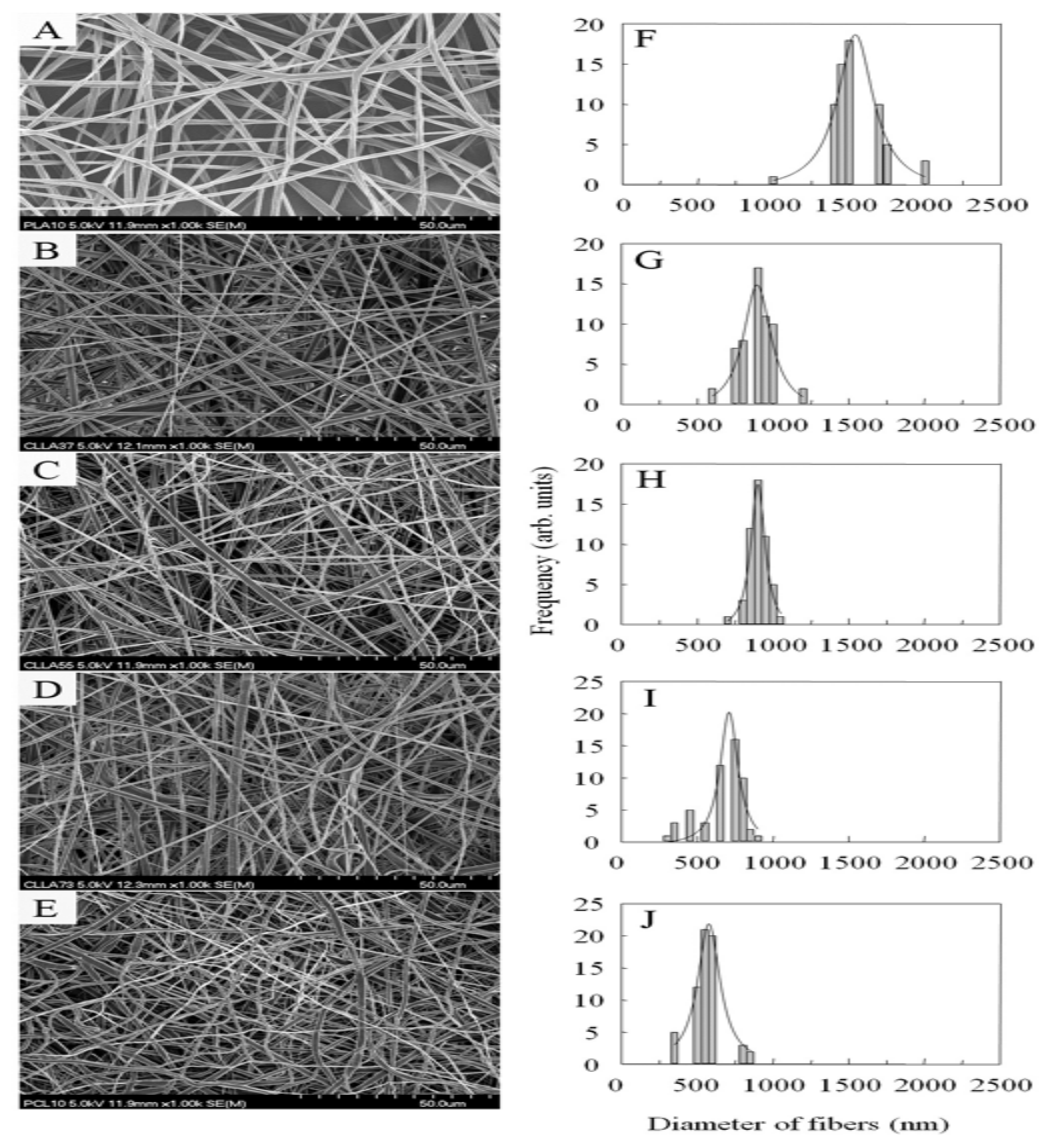

Figure 1: Ultrastructural morphology and fiber diameter distributions of PLA/PCL composites fabricated by the electrospinning technique. Microphotographs were made by SEM. (A) PLA $100 \%$, (B) PLA:PCL = 70:30, (C) PLA:PCL=50:50, (D) PLA:PCL=70:30, (E) PCL $100 \%$
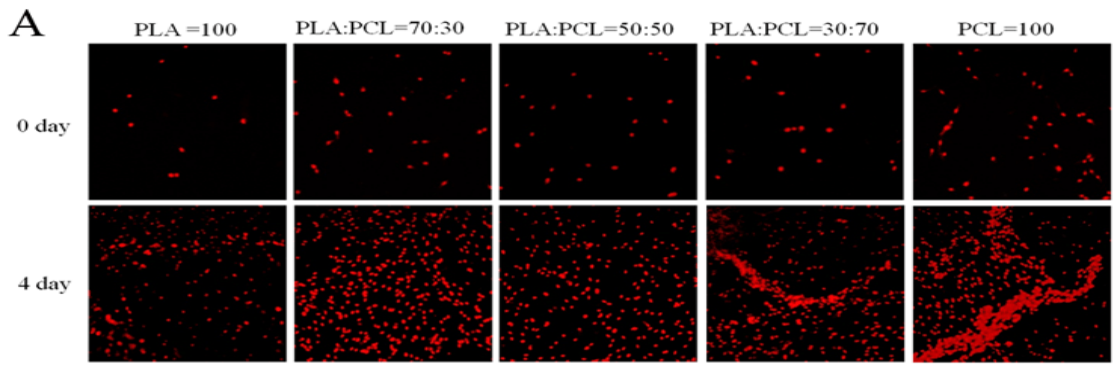

B

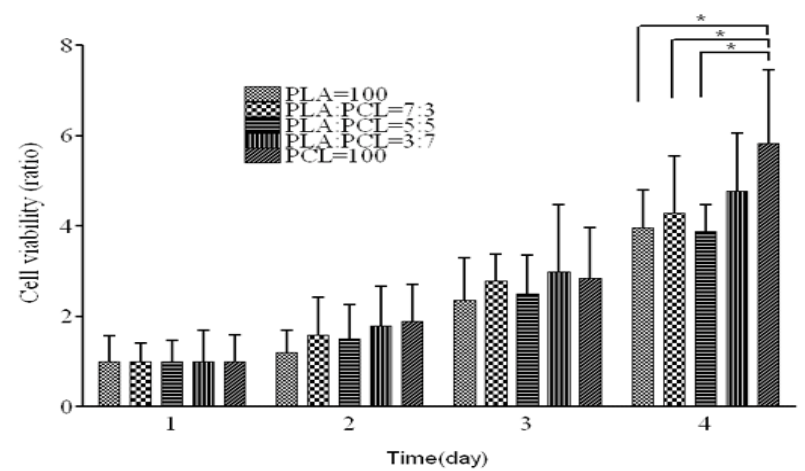

Figure 2: Cell proliferation on various PLA/PCL blended membranes. The proliferation of hMSC on the nanofibrous membrane was evaluated by an MTS assay and confirmed by PI staining. The hMSCs were seeded at a density of $2 \times 10^{5} \mathrm{cells} / \mathrm{cm}^{2}$ on various types of nanofibrous membranes put in a 12 -well plate. The cells were cultured in growth medium. MTS assay and PI staining were performed every $24 \mathrm{~h}$ for 4 days. Each time, the viable cells on the nanofibrous membranes were assessed by a microplate reader and photographed by confocal microscopy. The data is expressed as the mean $\pm S D$ and the significance was determined at ${ }^{*} p<0.1,{ }^{* *} p<0.05$ 

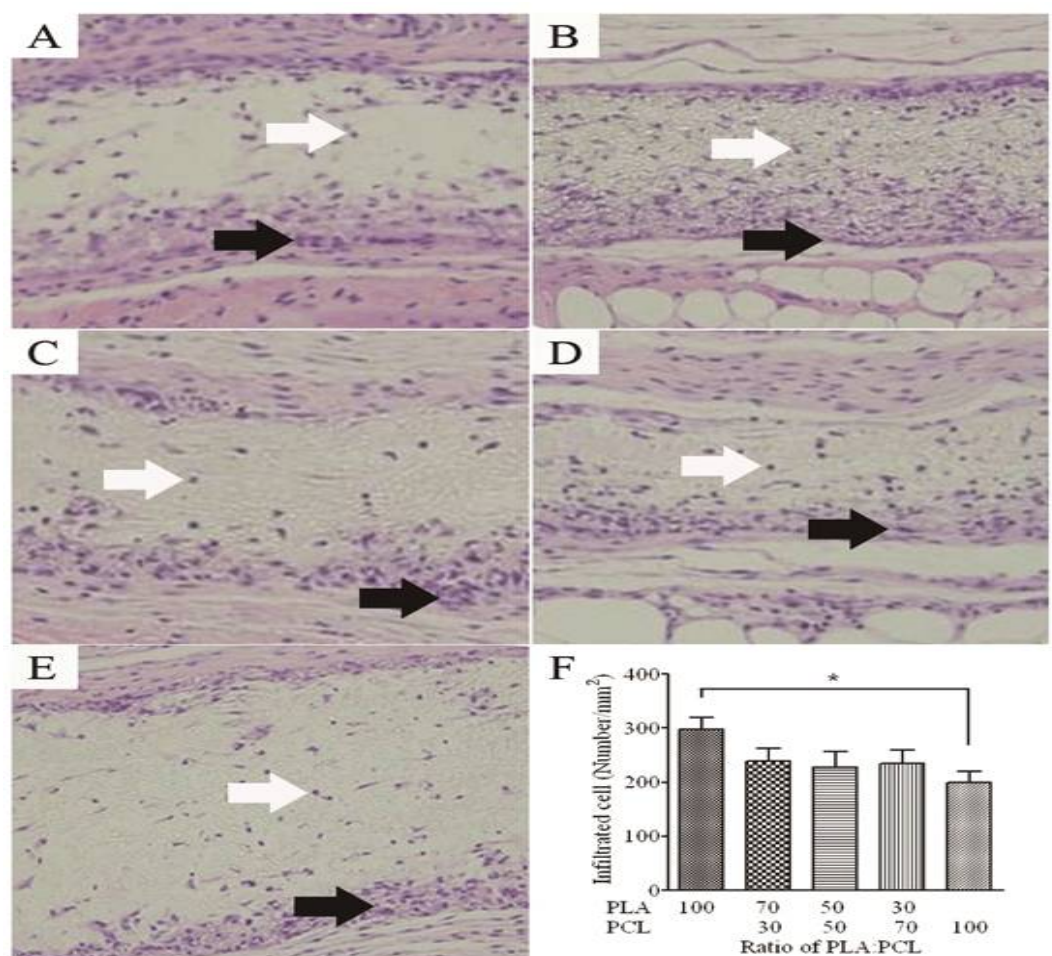

Figure 3: Histological analysis of the tissue adjacent to the nanofibrous membrane implanted subcutaneously in mice. The mice were sacrificed 2 weeks after various types of nanofibrous membranes were implanted. Multiple mononuclear elements, chiefly macrophages, and rare lymphocytes adhere to the membrane. Mild acute responses were observed in the PCL membrane. Some membranes exhibited fibrosis in the adjacent tissue. The slit under the membrane was probably due to artificial retraction of the tissue
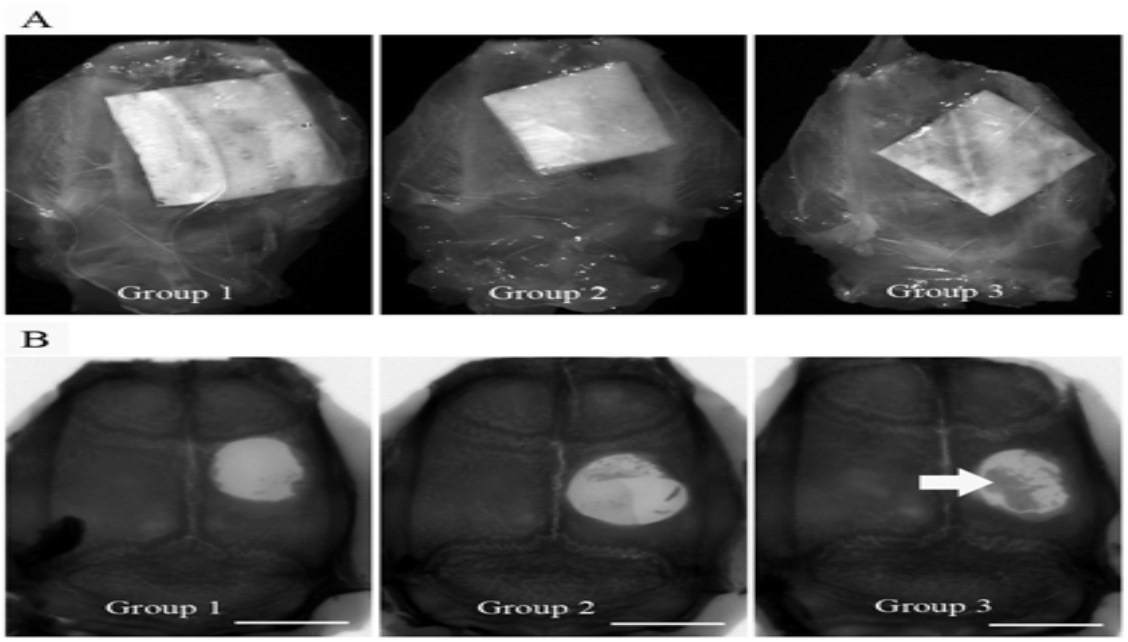

C

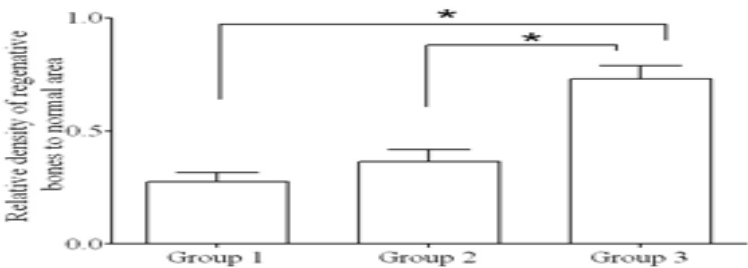

Figure 4: Photographs and soft X-rays of calvarial defects Bone marrow-derived stromal cells were isolated and maintained for passage three, and then plated onto $1 \mathrm{~cm} \times 1 \mathrm{~cm}$ of a square nanofibrous membrane at a density of $2 \times 10^{4}$ cells/sheet. The cells were cultured with/without differentiation induction medium for 7 days. One asymmetrical defect was made on the right side of the midline in each rat. The PCL membrane with the cells was placed over the defects, and after 4 weeks, the rats were euthanized, and the transplanted constructs were dissected carefully and free from the surrounding soft tissue. Photographs $(A)$ and microradiographs $(B)$ of the skull were taken using Image station FX 


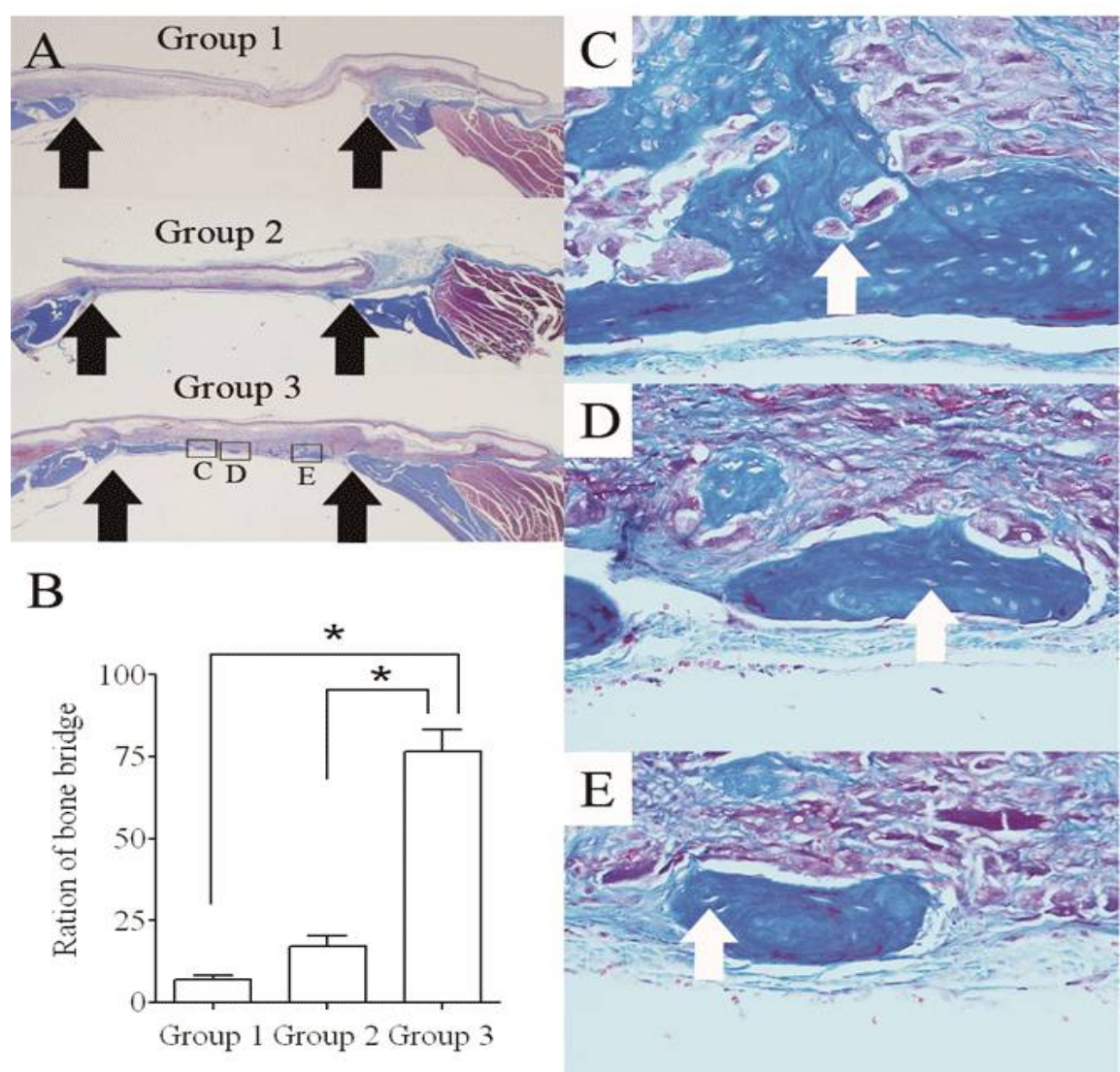

Figure 5: Histological analysis of rBMSCs-engrafted membranes for the bone regeneration of calvarial defects. Representative tissue sections of the defect sites covered with the membrane without $\operatorname{rBMSCs}(A$ and $D)$, the membrane with undifferentiated rBMSCs $(B$ and $E)$, and the membrane with differentiated rBMSCs (C and F) were stained by Mason-Trichome after 4 weeks. $(A),(B)$ and $(C)$ were with $\times 12.5,(D),(E)$ and $(F)$ were with $\times 100$ magnification. The initial lesion site of calvaria (fill triangle) and islands of bone formation (black arrow), and osteocyte in the canal (empty triangle) were marked.

Histological images of the implanted membranes 4 weeks after surgery are shown in Figure 5. Masson's Trichrome (MT) stained sections were analyzed with light microscopy at various levels of magnification, yielding information on the quality and histologic characteristics of bone regeneration. MT-stained Histological sections confirmed a significant amount of bone healing, consistent with the island of new bone in group 3 (Figure $5 \mathrm{~A}$ ), and also revealed a large number of collagen tissues near the island formation of new bone tissue. All of the newly formed bones tissues had osteocytes in the canal cavity (Figure 5 C, D, E).

In quantitative analysis (Figure 5B), the average of bony bridging ratios in the calvarial defects was $12.3 \%$ for PCL membranes only (Group 1), $22.2 \%$ for PCL membranes with non-induced rBMSC (Group 2), and $73.1 \%$ for PCL membranes with osteogenic induction of rBMSC (Group 3; Figure 5A, B). The bone bridging ratios histologically correspond well to Soft x-ray data obtained.

\section{DISCUSSION}

The fiber diameter, biocompatibility, and degradation rate of the blended polymers are essential for guided bone regeneration in dental surgery. This provides vital information regarding protection from soft tissue penetration during the hard tissue regeneration. Several observations have shown that pure PLA is hard and brittle and that adding PCL can change its original properties to make it softer and more flexible. The elongation properties of PLA increase with the addition of PCL, but the strength decreased as the elongation properties increased [8]. PLA can degrade more quickly than PCL, and so, it needs a shorter time to fully regenerate tissues of damaged organs. In other words, the addition of PCL to membranes hastens regeneration.

The fiber diameter of the blended polymers was estimated by SEM images. As shown in Fig. 1, fiber diameters of the blended polymers ranged from $500 \mathrm{~nm}$ to $1.5 \mu \mathrm{m}$. The relative fiber diameters of the blended polymers were ranked 
as following: PLA > PLA/PCL (7/3) > PLA/PCL $(5 / 5)>$ PLA/PCL $(3 / 7)>$ PCL. Many studies have reported that fibrous membranes blended with different biodegradable polymers by an electrospinning technique resulted in a range of diameter distributions from $10 \mathrm{~nm}$ to a few micrometer $[11,12]$.

Biocompatibility was addressed regarding in vitro viability and in vivo tissue response. From our results, viable cells were more abundant on the PCL fibrous membrane than other PLA/PCL blended membranes, and the dominant diameter of the PCL fibrous membranes are the smallest among the PLA/PCL blended membranes. The fiber diameter of the fibrous membranes affects cell proliferation, migration, and penetration in the membranes. The rat hippocampal astrocyte $(\mathrm{HA})$ and rat cerebro-microvascular endothelial cells (CEC) could penetrate to PCL microfibrous membranes, but not to PCL sub-microfibrous membranes [13]. For the viability of HUVECs, PCL membranes with a fiber diameter of $1.16 \pm$ $0.17 \mu \mathrm{m}$ were more suitable than ones with fiber dimensions of $7.02 \pm 1.03 \mu \mathrm{m}[14]$.

Several works demonstrated that electrospun fibrous membranes showed a minimized foreign body reaction in animal models in vivo, such as rat [15], rabbit [16] and sheep [17]. From our results, all membranes made of the blended polymers showed mild foreign body reaction, and the membrane with PCL had a lower inflammation than others, due to the less acidic products of degradation.

Recently, several studies focused on stem cell transplantation with several osteogenic factors, such as BMP-2 [18], fibroblast growth factor 2 [19], and the demineralized bone matrix [20], for bone regeneration in calvarial defect animal models. Moreover, multipotent adult stem cells seeded into the polyglycolic acid mesh can stimulate bone regeneration after 12 weeks, and without any osteogenic factors, in a rat calvarial defect model [21].

In the bone repairing animal model, transplantation with differentiated stem cells showed a better result than that with the control or undifferentiated stem cells [22,23]. These results are in agreement with our observation that the PCL fibrous membrane with osteogenic induction of rBMCs in the calvarial defect model stimulated a more compact bone regeneration than the one with non-induced rBMCs after 4 weeks. Furthermore, bone healing was observed in MT staining, which revealed areas of cortical bone with osteocytes.

\section{CONCLUSION}

The findings of the present study demonstrate that $100 \%$ PCL fibrous membrane shows better biocompatibility and viability than PLA blended forms, and that bone regeneration ability is improved on PCL sub-microfibrous membranes with osteogenic-induced cells, compared to that with non-induced cells in a calvarial defect model.

\section{DECLARATIONS}

\section{Acknowledgement}

This work was supported by Korea Institute of Planning and Evaluation for Technology in Food, Agriculture, Forestry and Fisheries(IPET) through High Value-added Food Technology Development Program, funded by Ministry of Agriculture, Food and Rural Affairs (MAFRA, no. 31606203).

\section{Conflict of Interest}

No conflict of interest associated with this work.

\section{Contribution of Authors}

The authors declare that this work was done by the authors named in this article and all liabilities pertaining to claims relating to the content of this article will be borne by them.

\section{Open Access}

This is an Open Access article that uses a funding model which does not charge readers or their institutions for access and distributed under the terms of the Creative Commons Attribution License (http://creativecommons.org/licenses/by 14.0) and the Budapest Open Access Initiative (http://www.budapestopenaccessinitiative.org/rea d), which permit unrestricted use, distribution, and reproduction in any medium, provided the original work is properly credited.

\section{REFERENCES}

1. Pektok E, Nottelet B, Tille JC, Gurny R, Kalangos A, Moeller $M$, Walpoth $B H$. Degradation and healing characteristics of small-diameter poly(epsiloncaprolactone) vascular grafts in the rat systemic arterial circulation. Circulation 2008; 118(24): 2563-2570.

2. Kumbar SG, Nukavarapu SP, James $R$, Nair LS, Laurencin CT. Electrospun poly(lactic acid-co-glycolic acid) scaffolds for skin tissue engineering. Biomaterials 2008; 29(30): 4100-4107. 
3. Panseri S, Cunha C, Lowery J, Del Carro U, Taraballi F, Amadio S, Vescovi A, Gelain F. Electrospun micro- and nanofiber tubes for functional nervous regeneration in sciatic nerve transections. BMC Biotechnol 2008; 8(39).

4. Yoshimoto $H$, Shin YM, Terai $H$, Vacanti JP. A biodegradable nanofiber scaffold by electrospinning and its potential for bone tissue engineering. Biomaterials 2003; 24(12): 2077-2082.

5. Yang $F$, Both SK, Yang $X$, Walboomers $X F$, Jansen JA. Development of an electrospun nano-apatite/PCL composite membrane for GTR/GBR application. Acta Biomater 2009; 5(9): 3295-3304.

6. Ko EK, Jeong SI, Rim NG, Lee YM, Shin H, Lee BK. In vitro osteogenic differentiation of human mesenchymal stem cells and in vivo bone formation in composite nanofiber meshes. Tissue Eng Part A 2008; 14(12): 2105-2119.

7. Shen $Y$, Sun $W$, Zhu KJ, Shen $Z$. Regulation of biodegradability and drug release behavior of aliphatic polyesters by blending. J Biomed Mater Res 2000; 50(4): 528-535.

8. Chen CC, Chueh JY, Tseng H, Huang HM, Lee SY. Preparation and characterization of biodegradable PLA polymeric blends. Biomaterials 2003; 24(7): 1167-1173.

9. Rutherford RB, Moalli M, Franceschi RT, Wang D, Gu K, Krebsbach $\mathrm{PH}$. Bone morphogenetic protein-transduced human fibroblasts convert to osteoblasts and form bone in vivo. Tissue Eng 2002; 8(3): 441-452.

10. Krebsbach PH, Gu K, Franceschi RT, Rutherford RB. Gene therapy-directed osteogenesis: BMP-7transduced human fibroblasts form bone in vivo. Hum Gene Ther 2000; 11(8): 1201-1210.

11. Ndreu A, Nikkola L, Ylikauppila H, Ashammakhi N, Hasirci V. Electrospun biodegradable nanofibrous mats for tissue engineering. Nanomedicine (Lond) 2008; 3(1) 45-60.

12. Li WJ, Cooper JA, Jr., Mauck RL, Tuan RS. Fabrication and characterization of six electrospun poly(alphahydroxy ester)-based fibrous scaffolds for tissue engineering applications. Acta Biomater 2006; 2(4): 377 385.

13. Baiguera S, Del Gaudio C, Fioravanzo L, Bianco A, Grigioni M, Folin M. In vitro astrocyte and cerebral endothelial cell response to electrospun poly(epsilon- caprolactone) mats of different architecture. J Mater Sci Mater Med 21(4): 1353-1362.

14. Mo XM, Xu CY, Kotaki M, Ramakrishna S. Electrospun $P(L L A-C L)$ nanofiber: a biomimetic extracellular matrix for smooth muscle cell and endothelial cell proliferation. Biomaterials 2004; 25(10): 1883-1890.

15. Cao H, McHugh K, Chew SY, Anderson JM. The topographical effect of electrospun nanofibrous scaffolds on the in vivo and in vitro foreign body reaction. $J$ Biomed Mater Res A 93(3): 1151-1159.

16. Chen ZC, Ekaputra AK, Gauthaman K, Adaikan PG, Yu $H$, Hutmacher DW. In vitro and in vivo analysis of coelectrospun scaffolds made of medical grade poly(epsilon-caprolactone) and porcine collagen. $J$ Biomater Sci Polym Ed 2008; 19(5): 693-707.

17. Saadai $P$, Nout YS, Encinas J, Wang A, Downing TL, Beattie MS, Bresnahan JC, Li S, Farmer DL. Prenatal repair of myelomeningocele with aligned nanofibrous scaffolds-a pilot study in sheep. J Pediatr Surg 46(12): 2279-2283.

18. Zellin G. Growth factors and bone regeneration. Implications of barrier membranes. Swed Dent J Suppl 1998; 129(7-65.

19. Kwan MD, Sellmyer MA, Quarto N, Ho AM, Wandless TJ, Longaker MT. Chemical control of FGF-2 release for promoting calvarial healing with adipose stem cells. $J$ Biol Chem 286(13): 11307-11313.

20. Gurevitch $O$, Kurkalli BG, Prigozhina $T$, Kasir J, Gaft A, Slavin S. Reconstruction of cartilage, bone, and hematopoietic microenvironment with demineralized bone matrix and bone marrow cells. Stem Cells 2003; 21(5): 588-597.

21. Taub PJ, Yau J, Spangler M, Mason JM, Lucas PA. Bioengineering of calvaria with adult stem cells. Plast Reconstr Surg 2009; 123(4): 1178-1185.

22. Dudas JR, Marra KG, Cooper GM, Penascino VM, Mooney MP, Jiang S, Rubin JP, Losee JE. The osteogenic potential of adipose-derived stem cells for the repair of rabbit calvarial defects. Ann Plast Surg 2006; 56(5): 543-548.

23. Yoon E, Dhar S, Chun DE, Gharibjanian NA, Evans GR. In vivo osteogenic potential of human adipose-derived stem cells/poly lactide-co-glycolic acid constructs for bone regeneration in a rat critical-sized calvarial defect model. Tissue Eng 2007; 13(3): 619-627. 